\title{
OPERATIONAL 333m BIOPHYSICAL PRODUCTS OF THE COPERNICUS GLOBAL LAND SERVICE FOR AGRICULTURE MONITORING
}

\author{
R. Lacaze ${ }^{\mathrm{a}, *}$, Bruno Smets ${ }^{\mathrm{b}}$, F. Baret ${ }^{\mathrm{c}}$, M. Weiss ${ }^{\mathrm{c}}$, D. Ramon ${ }^{\mathrm{a}}$, B. Montersleet ${ }^{\mathrm{a}}$, L. Wandrebeck ${ }^{\text {a }}$, J.-C. Calvet ${ }^{\mathrm{d}}$, J.-L. Roujean ${ }^{\mathrm{d}}$, \\ F. Camacho ${ }^{\mathrm{e}}$ \\ a HYGEOS, Euratechnologies, 165 avenue de Bretagne, 59000 Lille, France - rl@hygeos.com, dr@hgeos.com, bm@hygeos.com, \\ $1 \mathrm{w} @$ hygeos.com \\ ${ }^{\mathrm{b}}$ VITO, Boeretang 200, 2400 Mol, Belgium - bruno.smets@ vito.be \\ c INRA, EMMAH UMR1114, site Agroparc, 84914 Avignon, France - frederic.baret@ paca.inta.fr; marie.weiss@ paca.inra.fr \\ ${ }^{\mathrm{d}}$ CNRM/Météo-France, 42 avenue G. Coriolis, 31057 Toulouse Cedex, France - jean-christophe.calvet@meteo.fr, jean- \\ louis.roujean@meteo.fr \\ ${ }^{\text {e}}$ EOLAB, G.V. Marques del Turia, 20-9, 46005 Valencia, Spain - fernando.camacho@eolab.es
}

KEY WORDS: Copernicus, Service, bio-geophysical, agriculture, global, land, vegetation

\begin{abstract}
:
The Copernicus Global Land service provides continuously a set of bio-geophysical variables describing, over the whole globe, the vegetation dynamic, the energy budget at the continental surface and some components of the water cycle. These generic products serve numerous applications including agriculture and food security monitoring. The portfolio of the Copernicus Global Land service contains Essential Climate Variables like the Leaf Area Index (LAI), the Fraction of PAR absorbed by the vegetation (FAPAR), the surface albedo, the Land Surface Temperature, the soil moisture, the burnt areas, the areas of water bodies, and additional vegetation indices. They are generated every hour, every day or every 10 days on a reliable automatic basis from Earth Observation satellite data. Beside this timely production, the available historical archives have been processed, using the same innovative algorithms, to get consistent time series as long as possible. All products are accessible, free of charge after registration through FTP/HTTP (http://land.copernicus.eu/global/) and through the GEONETCast satellite distribution system. The evolution of the service towards the operations at $333 \mathrm{~m}$ resolution is partly supported by the FP7/ImagineS project which focuses on the retrieval of LAI, FAPAR, fraction of vegetation cover and surface albedo from PROBA-V sensor data. The paper presents the innovations of the $333 \mathrm{~m}$ biophysical products, make an overview of their current status, and introduce the next steps of the evolution of the Copernicus Global Land service.
\end{abstract}

\section{INTRODUCTION}

Since the $1^{\text {st }}$ January 2013, the global component of the Copernicus Land service, known as Global Land Service, continuously monitors the state of continental ecosystems providing a set of bio-geophysical products describing the state and the dynamics of the vegetation, the energy budget at the surface and some components of the water cycle.

\section{CURRENT STATIUS OF GLOBAL LAND SERVICE}

The Global Land Service is a global systematic monitoring service which generates a number of biophysical variables over the globe, in Near Real Time (NRT) every hour, every day or every 10 days, depending on the users' requirements, and the satellite sensors acquisition capabilities. Beside this timely production, the available historical archives of satellite input date have been processed to get consistent time series as long as possible.

The aim of the Global Land Service is to support and consolidate the policies and commitments of the European Union at international level for a wide range of applications such as the crop monitoring and food security inside and outside Europe, the monitoring of biodiversity, protected areas, and forest cover, the drought assessment and the desertification, the carbon modelling, the land use and land cover change, and the support to the Earth observation activities in Africa. The Global Land Service is also part of the EU contribution to GEO/GEOSS

\subsection{The Portfolio}

The products contained into the portfolio are gathered in 3 families describing (Table 1):

1. The vegetation state, dynamics and disturbances like the Leaf Area Index (LAI), the Fraction of photosynthethically active radiation absorbed by the vegetation (FAPAR), the fraction of green vegetation cover (FCover), the Dry Matter Productivity (DMP), the Normalized Difference Vegetation Index (NDVI), the Vegetation Condition Index (VCI), the Vegetation Productivity Index (VPI), and the maps of burnt areas

2. The energy budget at the interface between the surface and the atmosphere like the Top Of Canopy reflectance (TOC-ref), the Surface Albedo (SA) and the Land Surface Temperature (LST)

3. Some components of the water cycle like the Soil Water Index (SWI) and the maps of water bodies.

All products are generated over the globe. They are available within 3 days after the acquisition of the most recent

\footnotetext{
* Corresponding author. This is useful to know for communication with the appropriate person in cases with more than one author.
} 
observation used to create the product, except the LST and the SWI which are available within 1 day.

\begin{tabular}{|c|c|c|c|c|c|}
\hline \multirow[t]{2}{*}{ Variable } & \multirow{2}{*}{$\begin{array}{l}\text { Temporal } \\
\text { resolution }\end{array}$} & \multirow{2}{*}{$\begin{array}{c}\text { Spatial } \\
\text { resolution }\end{array}$} & \multicolumn{2}{|c|}{ NRT } & \multirow{2}{*}{$\begin{array}{l}\text { Archive } \\
\text { Sensor }\end{array}$} \\
\hline & & & Sensor & Status & \\
\hline LST & 1 hour & $0.05^{\circ}$ & $\Sigma \mathrm{Geo}$ & Op & $\Sigma \mathrm{Geo}$ \\
\hline SWI & 1 day & $0.1^{\circ}$ & $\begin{array}{l}\text { Metop / } \\
\text { ASCAT }\end{array}$ & Op & $\begin{array}{l}\text { Metop / } \\
\text { ASCAT }\end{array}$ \\
\hline \begin{tabular}{|l|} 
NDVI / \\
VCI / VPI \\
\end{tabular} & 10 days & $1 / 112^{\circ}$ & PROBA-V & Demo & SPOT/VGT \\
\hline DMP & 10 days & $1 / 112^{\circ}$ & PROBA-V & Demo & SPOT/VGT \\
\hline \begin{tabular}{|l|} 
LAI / \\
FAPAR / \\
FCover \\
\end{tabular} & 10 days & $1 / 112^{\circ}$ & PROBA-V & In dvlp & SPOT/VGT \\
\hline \begin{tabular}{|l|} 
Burnt \\
Area
\end{tabular} & 1 day & $1 / 112^{\circ}$ & PROBA-V & In dvlp & SPOT/VGT \\
\hline TOC-ref & 10 days & $1 / 112^{\circ}$ & PROBA-V & In dvlp & SPOT/VGT \\
\hline \begin{tabular}{|l|} 
Surface \\
Albedo
\end{tabular} & 10 days & $1 / 112^{\circ}$ & PROBA-V & In dvlp & SPOT/VGT \\
\hline \begin{tabular}{|l|} 
Water \\
Bodies \\
\end{tabular} & 10 days & $1 / 112^{\circ}$ & PROBA-V & In dvlp & SPOT/VGT \\
\hline
\end{tabular}

Table 1: Portfolio of the Global Land Service. "Op" means "operational", "demo" means "Demonstration", "In dvlp" means "in development".

Till end of 2013 , all $1 \mathrm{~km}$ resolution products $\left(1 / 112^{\circ}\right)$ were generated from the SPOT/VEGETATION sensor data. The continuity of the NRT production is ensured with the PROBA$\mathrm{V}$ sensor data. Note that, at the time this article is written, the PROBA-V products are still in development and not yet available to users. The Burnt Areas, the LAI, the FAPAR and the FCover should be made available in "Demonstration" mode (see §2.2) before mid-2015.

\subsection{The Quality Control}

The production is associated with a two-fold quality check: 1) a technical quality control is performed at each production center, and 2) an assessment of the scientific quality of products is carried out by expert teams.

During the production, automated tools monitor the individual processing steps to be check that the output files fit the expected characteristics, and their timeliness is compliant with the specifications $(\$ 2.1)$. Statistics are computed to verify that no unreliable values are present into the files.

A scientific quality assessment is performed per variable, for each new product or version, following the protocols and metrics defined by the Land Product Validation group of CEOS, when they exist. It mainly consists in indirect validation, i.e. inter-comparison with existing similar satellite-derived products, checking for the spatio-temporal consistency of products, and in direct validation, i.e. comparison with in-situ reference data when they exist and are available. In particular, the Global Land Service benefits from ground campaigns, conducted in the framework of the FP7 ImagineS project, which collect in-situ measurements, according to the sampling schemes and protocols defined by CEOS/LPV, and process them to retrieve reference high resolution maps. The resulting values are used to assess the accuracy of the satellite-derived biophysical products (Figure 1). The in-situ data and the reference maps are made available to the community through the ImagineS website at the address http://fp7imagines.eu/pages/services/ground-data.php.
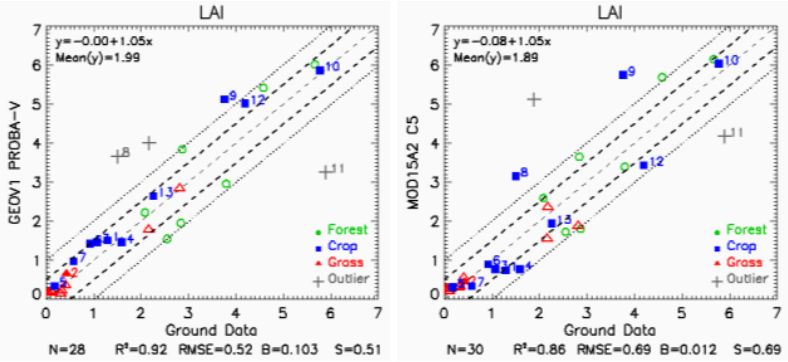

Figure 1: Comparison of satellite LAI product with the groundbased maps. Left side: PROBA-V GEOV1. Right side: MODIS C5. Filled symbols correspond to concomitant values of 2014 from ImagineS project and unfilled symbols to a different year.

Three levels of quality assessment are associated with three development stages of the products (Table 1):

1. "Demonstration": products are provided to users with a very limited commitment on the quality or availability of the service but they have been considered useful to be disseminated in order to enable users to test them and provide feedbacks. The demonstration phase ends with a limited quality assessment.

2. "Pre-operational": the limitations of the products are documented and can satisfy the majority of the applicable requirements and/or they have been considered useful for distribution to the users. The pre-operational phase ends with a full quality assessment.

3. "Operational": products have well documented nonrelevant limitations and largely satisfy the requirements applicable and/or have been considered mature enough for distribution to users. The operational phase regularly performs quality control.

In addition to the quality assessment, a quality monitoring, applying the same approach and metrics, is also carried out, every 6 months, on the "operational" products to check that their quality keeps stable along time. Further, an across variables quality monitoring is also performed, every 6 months, integrating the variables into a land surface model using a data assimilation scheme. The SWI and the LAI are assimilated over France $(8 \mathrm{~km} \times 8 \mathrm{~km})$ into the Land Data Assimilation system (LDAS) while a passive monitoring (i.e. comparison of model output resulting from the assimilation with the satellite products) of FAPAR, Surface Albedo and LST is also carried out. Here again, the Copernicus Global Land service benefits from the achievements of the ImagineS project which achieved upgrade and consolidation of the LDAS.

In parallel, an independent assessment of the service quality is organized through 2 bodies: 1) panel of external experts which give advices and recommendations on service evolution through half-yearly reviews; 2) a technical user committee which defines the product specifications.

\subsection{The Distribution}

The Global Land website, http://land.copernicus.eu/global, is the entry point for all information related to the service and the products. Individual product pages provide more details about the product status, its main characteristics in terms of algorithm, quality, technical properties, and applications. A set of 3 documents is associated with each product/version: 
1. the Algorithm Theoretical Basis Document (ATBD) which describes the retrieval methodology,

2. the Quality Assessment Report which presents the results of the validation exercise,

3. the Product User Manual which summarizes the algorithm and the validation results and includes a detailed description of technical characteristics of the product.

The website gives access to the distribution data portal. The access to the products is free and open, whatever the user category (public body or private company) and whatever the application (research or commercial use). Anonymous query is possible to search the products and check their availability. It is only necessary to register, through an automated procedure, before ordering and downloading the products. Two data dissemination channels exist: via internet where both the NRT and the historic (archive) products are accessible; via EUMETCast towards Africa and South-America where only the NRT products are distributed.

\section{EVOLUTION OF THE SERVICE}

The major next evolution of the service is the introduction into the portfolio of the $333 \mathrm{~m}$ products generated from the full resolution PROBA-V data. This evolution is partly supported by the ImagineS project which focuses on the LAI, FAPAR, FCover and surface albedo. ImagineS performs the research and development activities, i.e. defining innovative algorithms, assessing their performances and demonstrating their improvements comparing to previous methods, developing and qualifying the corresponding processing chains. The Global Land service integrates the qualified processing chain into its production unit, carries out the NRT processing associated with a continuous quality monitoring, and disseminates the products.

\subsection{Production at $333 \mathrm{~m}$ resolution}

The retrieval algorithms of LAI/FAPAR/FCover, on one hand, of the surface albedo, on the other hand, were defined by INRA and Meteo-France, respectively, in the framework of the FP7/ImagineS project.

\subsubsection{LAI/FAPAR/FCover retrieval methodology}

It is made of two steps as outlined in Figure 2.

The PROBA-V daily synthesis are the input data. First, they are translated into "SPOT/VGT-like" reflectances through a spectral correction. Then, they are corrected for atmospheric effects (ozone, water content, pressure) to get Top-of-Aerosols reflectances which are the input of neural networks (NNT) (one per variable). Only the reflectances inside a definition domain are used. Similarly, only the output of NNT inside the physical range and tolerance are kept. The NNT are trained with SPOT/VGT reflectances as input and the 'best' products derived from a combination of MODIS and CYCLOPES original products (Baret et al., 2007) similarly to what was achieved for SPOT/VGT LAI/FAPAR/FCover algorithm (Baret al al., 2013), which ensures the consistency between the $333 \mathrm{~m}$ PROBA-V products and the $1 \mathrm{~km}$ SPOT/VGT products.

Step B is a compositing and gap filling module. According to the pixel identification (Evergreen Broadleaf Forest (EBF) or not, based upon the time series of daily estimates or the Globcover land cover map (http://www.esa-landcover-cci.org ) when the time series does not provide a reliable identification of the vegetation class), the temporal smoothing is performed with specific parameters. Finally, a post-processing module is applied to fill the small gaps by linear interpolation.

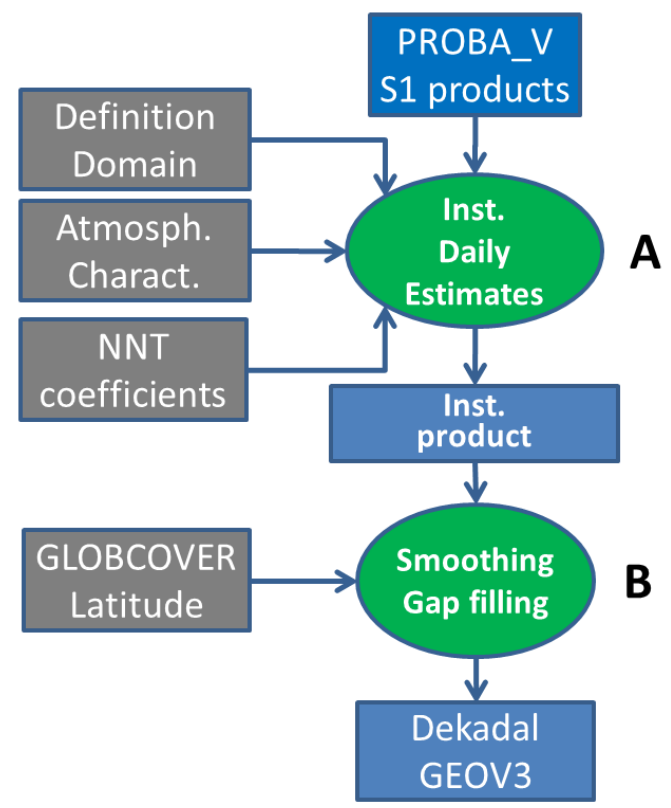

Figure 2: Flow chart of the LAI/FAPAR/FCover algorithm

HYGEOS has translated this algorithm into a software compliant with the coding specifications and the processing performances of the Global Land service. After its technical qualification and the thematic verification of the output products, the chain has been delivered to the Global Land service that should start the NRT production over Europe mid2015. In parallel, in the framework of ImagineS, VITO will perform offline production over identified areas outside Europe where local expert teams will make a utility assessment of the products.

\subsubsection{Surface Albedo retrieval methodology}

The outline of the methodology is depicted in Figure 3.

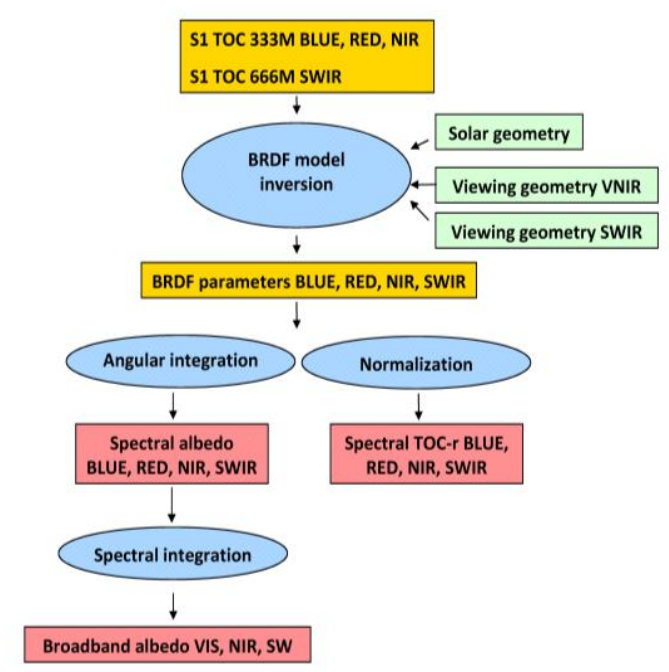

Figure 3: Flow chart of the surface albedo algorithm 
The calculation of surface albedo and the normalized TOC-ref requires the knowledge of the complete bi-directional reflectance distribution function (BRDF) of the surface. A semiempirical kernel-based reflectance model (Roujean et al., 1992) is adjusted to the measurements. This delivers an estimate of the complete angular dependence of the bi-directional reflectance factor in each spectral channel of the sensor. The proposed algorithm consists in calculating the "black-sky" and "whitesky" albedos in all instrument channels by using the coefficients provided by the directional reflectance model inversion. The narrow- to broadband conversion is performed with a linear regression formula.

This methodology is the same than the one used to generate the Surface Albedo products at $1 \mathrm{~km}$ resolution (Table 1). The differences are related to the time compositing for the model inversion (20 days instead of 30 days) and in the temporal resolution of the products ( 5 days instead of 10 days). A shorter compositing period is possible because a finer spatial resolution allows a better cloud decontamination. Regarding the finer frequency, it will allow, in a further evolution step, to discriminate the albedo from bare soil and from vegetation.

Starting from a prototype delivered by Meteo-France, HYGEOS has developed the input and output modules able to ingest the PROBA-V Top-Of-Canopy daily synthesis and to create the albedo products according to the Global Land service specifications. It has been checked that the processing performances were compliant with the product timeliness. After verification of the output product consistency, the chain will be delivered to the Global Land service that should start the NRT production before the end of 2015 .

\subsubsection{Application for agriculture monitoring}

The agricultural production is achieved per species since the markets are organized in such a way. This has strong implications on the remote sensing products required for agriculture monitoring: the acreage of each crop/fodder should be known accurately concurrently with the associated productivity. The use of $333 \mathrm{~m}$ resolution observations will improve greatly the performance of global agricultural monitoring services, currently based on kilometric resolution images of mixed (several crops/fodder fields, natural areas) pixels.

\subsection{Long-term evolution}

At longer term, the evolution of the Global Land Service will ensure a sustainable global monitoring of the continental ecosystems with the continuity of $1 \mathrm{~km}$ and $333 \mathrm{~m}$ biophysical products generated from PROBA-V and Sentinel-3. A further step towards a production at $100 \mathrm{~m}$ could be envisaged if users expressed such requirements. In parallel, a "worldwide" monitoring of hot-spots, like the major protected areas, will be added in the service, providing biophysical products derived from Sentinel-2 data at resolution between $10 \mathrm{~m}$ and $10 \mathrm{~m}$, depending of the needs.

Further, the current biophysical products will benefit from the capabilities of the new sensors. For instance, a $1 \mathrm{~km}$ resolution SWI product is in preparation, using jointly the Metop/ASCAT and Sentinel-1/SAR data.

Finally, new variables will be included into the service portfolio, according to the users' requirements. Some candidate variables are the phenology, the snow extent, or the water level of lakes and rivers.

\section{CONCLUSION}

The Copernicus Global Land service is operational providing sustainable NRT delivery of global products, associated with consistent historic time series. A continuous quality monitoring guaranties the product quality reached a level satisfying the users' requirements and keeps stable along time. The access to products is free and open through http://land.copernicus.eu/global/. Continuing the $1 \mathrm{~km}$ products time series with the replacement of the SPOT/VEGETATION sensor by the PROBA-V sensor was challenging: some products are still in development. Full quality assessment of PROBA-V products is ongoing.

The next major evolution of the Global Land service is the production of a number of biophysical variables at $333 \mathrm{~m}$ resolution from the PROBA-V sensor data. This is a first step before using jointly the data of PROBA-V and Sentinel-3 that should be launch before end 2015 .

\section{CONTACTS}

For the Copernicus Global Land service:

- Website: http://land.copernicus.eu/global

- Coordinator: bruno.smets@vito.be

- S\&T contact: rl@hygeos.com

- Helpdesk: helpdeskticket@vgt.vito.be

- Contract Management: copernicuslandproducts@jrc.ec.europa.eu

- Consortium:

○ Leader: VITO

- Partners: HYGEOS, IPMA, Meteo-France, ZAMG

- Associates: EOLAB, INRA, CREAF, TU Wien, University of Leicester

For the ImagineS project:

- Website: http://fp7-imagines.eu

- Coordinator: HYGEOS - rl@hygeos.com

- Consortium: ECMWF, EOLAB, INRA, MeteoFrance, OMSZ, UCL, VITO

\section{REFERENCES}

Baret, F., M. Weiss, R. Lacaze, F. Camacho, H. Makhmara, P. Pacholcyzk, B. Smets, 2013. GEOV1: LAI and FAPAR essential climate variables and FCOVER global time series capitalizing over existing products. Part1: Principles of development and production. Remote Sensing of Environment 137: 299-309.

Baret, F., Hagolle, O., Geiger, B., Bicheron, P., Miras, B., Huc, M., Berthelot, B., Weiss, M., Samain, O., Roujean, J.L., Leroy, M., 2007. LAI, fAPAR and fCover CYCLOPES global products derived from VEGETATION. Part 1: Principles of the algorithm. Remote Sensing of Enviroment 110, 275-286.

Roujean J.-L., M. Leroy, and P.-Y. Deschamps, 1992, A bidirectional reflectance model of the Earth's surface for the correction of remote sensing data, Journal of Geophysical Research, 97(D18), 20455-20468. 